\title{
HUBUNGAN ANTARA PEKERJAAN DAN AKTIVITAS FISIK DENGAN KEJADIAN DIABETES MELLITUS DI KLINIK MARDI WALUYO KABUPATEN LAMPUNG TENGAH
}

\author{
Resti Arania1, Tusy Triwahyuni², Toni Prasetya ${ }^{3}$, Sekar Dwi Cahyani ${ }^{4}$ \\ ${ }^{1}$ Depertemen Patologi Anatomi Fakultas Kedokteran Universitas Malahayati \\ ${ }^{2}$ Departemen Parasitologi Fakultas Kedokteran Universitas Malahayati \\ ${ }^{3}$ Departemen Penyakit Dalam Fakultas Kedokteran Universitas Malahayati \\ ${ }^{4}$ Program Studi Kedokteran Fakultas Kedokteran Universitas Malahayati
}

[email korespondensi: sekardwic22@gmail.com]

\begin{abstract}
Relationship Between Work and Physical Activities and The Event Of Mellitus Diabetes At Mardi Waluyo ClinicCentral Lampung District In 2020. Diabetes mellitus is a chronic disease that can occur when the body cannot produce enough insulin, which is a body hormone that can regulate blood sugar due to a disturbance in the pancreas, or a condition in which the body cannot use the insulin produced by the body. Diabetes mellitus is one of 4 non-communicable diseases that needs to be followed up. Risk factors for non-communicable diseases, especially diabetes, are often related to lifestyle, the death rate caused by noncommunicable diseases such as diabetes mellitus is more common in developing countries than in developed countries. The purpose of this study was to determine the relationship between work and physical activity with the incidence of diabetes mellitus at the Mardi Waluyo Clinic, Central Lampung in 2020. This research method is observational analytic with a cross sectional approach, the data obtained is secondary data obtained from the medical records of diabetes patients. mellitus and primary data in the form of a physical activity questionnaire. The study was conducted from October 2020 to February 2021. Sampling using the Lemeshow formula with an unknown population to obtain 126 samples. The analysis that will be used is bivariate analysis with the Spearman Correlation test. Results obtained from 126 respondents suspect diabetes mellitus, as many as 93 respondents had diabetes mellitus $(73.8 \%)$. Of the 93 respondents who experienced diabetes mellitus, as many as 47 respondents had low physical activity (94.0\%) with a value $(p=0000)$ and as many as 42 respondents $(89.4 \%)$ did not have a job with a value $(p=0.002)$. The conclusion in this study is that there is a relationship between work and physical activity with the incidence of diabetes mellitus at the Mardi Waluyo Clinic, Central Lampung in 2020.
\end{abstract}

Keywords: Diabetes Mellitus, Occupation, Physical Activity

\begin{abstract}
Abstrak: Hubungan Antara Pekerjaan dan Aktivitas Fisik dengan Kejadian Diabetes Mellitus Di Klinik Mardi WaluyoKabupaten Lampung Tengah Tahun 2020. Diabetes mellitus merupakan penyakit kronik yang dapat terjadi disaat tubuh tidak dapat memproduksi insulin yang cukup yaitu hormon tubuh yang dapat mengatur gula dalam darah yang disebabkan karena adanya gangguan pada pankreas, atau kondisi dimana tubuh tidak dapat menggunakan insulin yang diproduksi oleh tubuh. Diabetes mellitus adalah salah satu dari 4 penyakit tidak menular yang perlu ditindak lanjuti. Faktor resiko penyakit tidak menular khususnya diabetes ini seringkali berkaitan dengan gaya hidup, angka kematian yang disebabkan oleh penyakit tidak menular seperti diabetes mellitus ini lebih sering terjadi di negara yang berkembang dibanding negara yang maju. Tujuan Penelitian ini adalah Untuk mengetahui adanya hubungan antara pekerjaan dan aktivitas fisik dengan kejadian diabetes mellitus di Klinik Mardi Waluyo Lampung Tengah tahun 2020. Metode Penelitian ini bersifat observasional analitik dengan
\end{abstract}


pendekatan cross sectional, data yang diperoleh berupa data sekunder yang diperoleh dari rekam medis pasien diabetes mellitus dan data primer berupa kuesioner Aktivitas Fisik. Penelitian dilakukan dari bulan Oktober 2020 hingga Februari 2021. Pengambilan sampel dengan menggunakan rumus Lemeshow dengan populasi tidak diketahui sehingga mendapatkan 126 sampel. Analisis yang akan digunakan adalah analisis bivariat dengan uji Korelasi Spearman. Hasil yang didapat Dari 126 responden suspect diabetes mellitus, sebanyak 93 orang responden mengalami diabetes mellitus $(73,8 \%)$. Dari 93 orang responden yang mengalami diabetes mellitus, sebanyak 47 orang responden beraktivitas fisik rendah $(94,0 \%)$ dengan nilai $(p=0000)$ dan sebanyak 42 orang responden $(89,4 \%)$ tidak memiliki pekerjaan dengan nilai $(p=0.002)$. Kesimpulan pada penelitian ini adalah Terdapat hubungan antara pekerjaan dan aktivitas fisik dengan kejadian diabetes mellitus di Klinik Mardi Waluyo Lampung Tengah tahun 2020.

Kata Kunci: Diabetes Mellitus, Pekerjaan, Aktivitas Fisik

\section{PENDAHULUAN}

Berdasarkan berjalannya waktu, terjadinya perubahan transisi epidemiologi penyakit yang akan datang pada masyarakat, dimana terjadi peralihan penyakit yaitu dari penyakit menular ke penyakit tidak menular. Wilayah yang sekiranya akan terjadi peningkatan Penyakit Tidak Menular atau PTM ini terdapat di berbagai belahan dunia, yaitu sebesar kurang lebih dari $20 \%$ akan terjadi di beberapa wilayah di Afrika, dapat terjadi pula di Asia Tenggara dan di Mediterania Timur (Remais et al, 2012). Faktor resiko penyakit tidak menular ini seringkali berkaitan dengan gaya hidup, angka kematian yang disebabkan oleh penyakit tidak menular seperti diabetes mellitus ini lebih sering terjadi di negara yang berkembang dan berpenghasilan rendah hingga menengah dibanding negara yang maju.

Diabetes mellitus merupakan penyakit kronik yang dapat terjadi disaat tubuh tidak dapat memproduksi insulin yang cukup yaitu hormon tubuh yang dapat mengatur gula dalam darah yang disebabkan karena adanya gangguan pada pankreas, atau kondisi dimana tubuh tidak dapat menggunakan insulin yang diproduksi oleh tubuh. Diabetes mellitus adalah salah satu dari 4 penyakit tidak menular yang perlu ditindak lanjuti. Diketahui bahwa dalam beberapa dekade terakhir, jumlah kasus diabetes dan prevalensi diabetes terus meningkat (WHO, 2016).
Pada tahun 2010, WHO memperkirakan di tahun 2014, hampir 422 juta orang berusia diatas 18 tahun berisiko terkena diabetes. Diperkirakan resiko terbesar terkena diabetes mellitus berada di Asia Tenggara dan Pasifik Barat. Antara tahun 1980 dan 2014, jumlah orang dengan penyakit diabetes mellitus di seluruh dunia meningkat hingga 4x lipat dari 108 juta orang penderita menjadi 422 juta orang penderita.

Berdasarkan dari konsensus PERKENI tahun 2015, angka kejadian penyakit diabetes mellitus (DM) di Indonesia mencapai $6,9 \%$ pada tahun 2013 dan pada tahun 2018 meningkat menjadi10,9\%. Hal ini menunjukkan bahwa prevalensi diabetes di Indonesia terus mengalami peningkatan (RISKESDAS, 2018).

Menurut Riset Kesehatan Dasar, prevalensi diabetes mellitus seringkali lebih tinggi pada masyarakat yang tingkat pendidikannya tinggi. Pada tahun 2009, kejadian prediabetes di poli rawat jalan di Provinsi Lampung ratarata mencapai 365 orang per bulan, dan meningkat menjadi 1.103 orang pada tahun 2010. Sementara berdasarkan data dari Dinas Kesehatan Lampung Tengah, kejadian diabetes mellitus di Kabupaten Lampung Tengah mengalami peningkatan kasus sebesar $9 \%$ atau mencapai 581 kasus (Irwan, 2010).

Teori yang menghubungkan antara diabetes mellitus dengan pekerjaan dan aktivitas fisik berdasarkan dari penelitian sebelumnya 
yang terkait penelitian diatas yaitu penelitian dari Gabby (2017) terbukti bahwa terdapat hubungan antara pekerjaan dengan kejadian diabetes mellitus pada pasien poli rawat jalan di RSUP Prof. Dr. R. D. Kandou Manado dan berdasarkan hasil penelitian dari Ronika Sipayung dkk, terbukti bahwa terdapat hubungan antara aktivitas fisik dengan kejadian diabetes mellitus di Puskesmas Padang Bulan Medan tahun 2017.

Berdasarkan dari latar belakang yang terdapat di atas, karena masih meningkatnya kasus penyakit diabetes yang terjadi baik di Dunia, di Indonesia, dan di Lampung khususnya Lampung Tengah,maka peneliti tertarik untuk meneliti tentang hubungan antara pekerjaan dan aktivitas fisik dengan angka kejadian diabetes mellitus (DM) di Klinik Mardi Waluyo kabupaten Lampung Tengah tahun 2020.

\section{METODE}

Penelitian ini bersifat observasional analitik dengan pendekatan cross sectional, data yang diperoleh berupa data sekunder yang diperoleh dari rekam medis pasien suspect diabetes mellitus dan data primer berupa kuesioner Aktivitas Fisik. Penelitian dilakukan dari bulan Oktober 2020 hingga Februari 2021. Pengambilan sampel dengan menggunakan rumus Lemeshow dengan populasi tidak diketahui sehingga mendapatkan 126 sampel. Analisis yang akan digunakan adalah analisis bivariat dengan uji Korelasi Spearman.

\section{HASIL}

Tabel 1. Distribusi Frekuensi Responden Berdasarkan Aktivitas Fisik dan Pekerjaan di Klinik Mardi Waluyo Lampung Tengah Tahun 2020

\begin{tabular}{llll}
\hline No. & Karakteristik & Jumlah & Persentase \\
\hline 1 & Aktivitas fisik & & \\
& \multicolumn{1}{c}{ Rendah } & 50 & $39.7 \%$ \\
& & 37 & $29.4 \%$ \\
& Tinggi & 39 & $31.0 \%$ \\
\hline 2 & $\begin{array}{l}\text { Pekerjaan } \\
\text { Tidak bekerja }\end{array}$ & 47 & $37.2 \%$ \\
& Bekerja & 79 & $62.7 \%$ \\
\hline
\end{tabular}

Dari hasil penelitian didapatkan distribusi frekuensi responden berdasarkan aktivitas fisik kelompok rendah sebanyak 50 orang (39.7\%), sedang sebanyak 37 orang $(29.4 \%)$ dan tinggi sebanyak 39 orang (31.0\%). Dan pada pekerjaan responden yang tidak bekerja sebanyak 47 orang $(37.2 \%)$, dan yang bekerja sebanyak 79 orang $(62.7 \%)$. Dan pada penyakit diabetes mellitus responden yang tidak mengalami diabetes mellitus sebanyak 33 orang $(26.2 \%)$, dan yang mengalami diabetes mellitus sebanyak 93 orang (73.8\%) (Tabel 1).

Tabel 2. Distribusi Frekuensi Responden Berdasarkan Penyakit Diabetes Mellitus di Klinik Mardi Waluyo Lampung Tengah Tahun 2020

\begin{tabular}{llll}
\hline No. & Karakteristik & Jumlah & Persentase \\
\hline 1 & Diabetes Mellitus & & \\
& Tidak diabetes mellitus & 33 & $26.2 \%$ \\
& Diabetes mellitus & 93 & $73.8 \%$ \\
\hline
\end{tabular}


Dari hasil penelitian didapatkan distribusi frekuensi responden yang tidak mengalami diabetes mellitus sebanyak 33 orang (26.2\%), dan yang mengalami diabetes mellitus sebanyak 93 orang $(73.8 \%)$ (Tabel 2$)$.

Tabel 3. Hasil Uji Spearman Hubungan Aktivitas Fisik dan Pekerjaan dengan Kejadian Diabetes Mellitus Klinik Mardi Waluyo Lampung Tengah Tahun 2020

\begin{tabular}{lllll}
\hline \multirow{2}{*}{ No } & \multirow{2}{*}{ Variabel } & \multicolumn{2}{l}{ Diabetes Mellitus } & Keterangan \\
\cline { 3 - 4 } & & $\mathbf{P}$ & $\mathbf{R}$ & \\
\hline 1 & Aktivitas Fisik & 0,000 & -0.489 & Ada Hubungan yang Sedang \\
2 & Pekerjaan & 0,002 & -0.273 & Ada Hubungan yang Lemah \\
\hline
\end{tabular}

Hasil analisis hubungan antara aktivitas fisik dengan kejadian diabetes mellitus dengan diperoleh nilai $p$-value $=0.000$. Hal ini menunjukkan bahwa ada korelasi yang sedang antara aktivitas fisik dengan kejadian diabetes mellitus dengan korelasi sebesar -0.489 yang menunjukkan bahwa semakin tinggi aktivitas fisik seseorang semakin dapat menekan kejadian diabetes mellitus.

Hasil analisis hubungan antara pekerjaan dengan kejadian diabetes mellitus dengan diperoleh nilai $\mathrm{p}$-value $=0.002$. Hal ini menunjukkan bahwa ada korelasi yang lemah antara pekerjaan dengan kejadian diabetes mellitus dengan nilai korelasi sebesar 0.273 yang menunjukkan bahwa seseorang yang bekerja dengan aktivitas fisik yang tinggi dapat menekan kejadian diabetes mellitus (Tabel 3).

\section{PEMBAHASAN}

\section{Aktivitas Fisik}

Aktivitas fisik adalah gerakan yang dihasilkan oleh otot-otot rangka pada tubuh sebagai pengeluaran tenaga berupa pekerjaan, waktu senggang, dan aktivitas sehari-hari (KEMENKES, 2015). Aktivitas fisik merupakan salah satu pilar pengelolaan diabetes mellitus yang berguna untuk memperbaiki sensitivitas insulin dan juga untuk menjaga kebugaran tubuh. Aktivitas fisik bisa membantu dalam terserapnya glukosa ke dalam sel tanpa membutuhkan insulin, selain itu aktivitas fisik juga bisa untuk menurunkan berat badan penderita diabetes yang obesitas serta mencegah laju progresivitas gangguan toleransi glukosa menjadi diabetes mellitus (Tjokroprawiro, 2012). Hasil penelitian ini sejalan dengan penelitian Nonita (2019) dimana sebagian besar intensitas aktivitas fisik responden yang mengalami diabetes adalah ringan/rendah (53.3\%). Sama halnya juga dengan penelitian yang dilakukan oleh Fharitz (2018) dimana 79.4\% pasien melakukan aktivitas fisik ringan.

\section{Pekerjaan}

Pekerjaan yaitu proses seseorang berusaha untuk memperoleh penghasilan di suatu perusahaan/instansi untuk memenuhi kebutuhan sehari-hari baik itu pekerjaan sektor formal/informal. American Diabetes Association (ADA) (2012) menyatakan bahwa seseorang yang bekerja memiliki manfaat yang besar karena kadar glukosa darah dapat terkontrol melalui aktivitas fisik serta mencegah terjadi komplikasi. Faktor pekerjaan mempengaruhi resiko besar terjadinya diabetes mellitus, pekerjaandengan aktivitas fisik yang ringan akan menyebabkan kurangnya pembakaran energi oleh tubuh sehingga kelebihan energi dalam tubuh akan disimpan dalam bentuk lemak dalam tubuh yang mengakibatkan obesitas yang merupakan salah satu faktor resiko diabetes mellitus (Suiraoka, 2012). Hasil penelitian di atas sejalan dengan penelitian Risma (2019) dimana sebagian besar responden adalah bekerja $70.8 \%$. Hal ini sejalan dengan penelitian Adnan bahwa sebagian besar sampel adalah sebagai ibu rumah tangga yaitu sebanyak 22 orang (59,5\%). Dan hasil penelitian Gabby (2017) menunjukkan bahwa terdapat 
hubungan yang bermakna antara status pekerjaan tidak bekerja dengan diabetes mellitus Tipe 2 .

\section{Kejadian Diabetes Mellitus}

Diabetes mellitus merupakan penyakit kronik yang dapat terjadi disaat tubuh tidak dapat memproduksi insulin yang cukup yaitu hormon tubuh yang dapat mengatur gula dalam darah yang disebabkan karena adanya gangguan pada pankreas, atau kondisi dimana tubuh tidak dapat menggunakan insulin yang diproduksi oleh tubuh. Diabetes mellitus adalah salah satu dari 4 penyakit tidak menular yang perlu ditindak lanjuti. Diketahui bahwa dalam beberapa dekade terakhir, jumlah kasus diabetes dan prevalensi diabetes terus meningkat (WHO, 2016). Penyakit ini tidak hanya menyerang orang dewasa, tetapi juga dapat menyerang anakanak. Diabetes mellitus ditandai dengan peningkatan kadar gula dalam darah yang disebabkan oleh terganggunya produksi insulin, gangguan kerja insulin, atau keduanya (Skyler, 2017).

Faktor risiko DM tipe 2 dikategorikan menjadi beberapa faktor yaitu sosiodemografi, riwayat kesehatan, pola hidup, dan kondisi klinis serta mental. Adapun faktor sosiodemografi terdiri dari umur, jenis kelamin, pendidikan dan pekerjaan. Sedangkan faktor riwayat kesehatan mencakup riwayat penyakit keturunan diabetes mellitus dalam keluarga dan berat lahir. Faktor-faktor pola hidup itu terdiri dari aktivitas fisik, konsumsi sayur dan buah, paparan asap rokok serta konsumsi alkohol. Sementara itu, faktor kondisi klinis dan mental pasien itu terdiri dari lingkar pinggang, tekanan darah, indeks massa tubuh dan stres (Irwan, 2010).

\section{Hubungan Antara Aktivitas Fisik dengan Kejadian Diabetes Mellitus}

Hasil penelitian di atas sejalan dengan penelitian Nonita (2019) dimana dari hasil analisis bivariat menunjukkan ada hubungan aktivitas fisik terhadap kejadian diabetes mellitus dengan diperoleh nilai $\mathrm{p}$-value $=0.009$. Penelitian ini juga sejalan dengan penelitian Zahtamal (2007) tentang faktor-faktor resiko pasien DM di daerah Riau dengan nilai taraf signifikan $p<0.05$. Hasil penelitian ini juga sejalan dengan penelitian Nonita (2019) dimana sebagian besar intensitas aktivitas fisik responden yang mengalami diabetes adalah ringan/rendah (53.3\%). Sama halnya juga dengan penelitian yang dilakukan oleh Fharitz (2018) dimana $79.4 \%$ pasien melakukan aktivitas fisik ringan.

Aktivitas fisik adalah setiap gerakan tubuh yang dihasilkan oleh otot rangka yang memerlukan energi. Kurangnya aktivitas fisik merupakan faktor risiko independen untuk penyakit kronis dan secara keseluruhan diperkirakan menyebabkan kematian secara global. Pengaruh aktivitas fisik seperti olahraga secara langsung berhubungan dengan peningkatan kecepatan pemulihan glukosa otot. Saat beraktivitas, otot menggunakan glukosa yang tersimpan dalam otot dan jika glukosa berkurang, otot mengisi kekosongan dengan mengambil glukosa dari darah. Hal ini akan mengakibatkan menurunnya glukosa darah sehingga memperbesar pengendalian glukosa darah (Barnes, 2011).

Aktivitas fisik merupakan kunci dalam pengelolaan diabetes mellitus terutama sebagai pengontrol gula darah dan memperbaiki faktor risiko kardiovaskuler seperti menurunkan hiperinsulinemia, meningkatkan sensitivitas insulin, menurunkan lemak tubuh, serta menurunkan tekanan darah. Aktivitas fisik yang teratur berhubungan dengan penurunan angka mortalitas sekitar $45-70 \%$ pada populasi diabetes mellitus tipe II serta menurunkan kadar $\mathrm{HbA} 1 \mathrm{c}$ ke level yang bisa mencegah terjadinya komplikasi. Aktivitas fisik seperti berolahraga minimal 150 menit setiap minggu yang terdiri dari latihan aerobic, latihan ketahanan maupun kombinasi dari keduanya berkaitan dengan penurunan kadar HbA1c pada penderita diabetes mellitus tipe2 (Astuti, 2016).

Dari hasil penelitian di atas peneliti berpendapat bahwa aktivitas fisik berupa olahraga merupakan bagian 
penting dalam pengobatan dan pencegahan diabetes mellitus. Olahraga membantu penderita untuk meningkatkan kesensitifitasan insulin, mengontrol berat badan dan meningkatkan kesehatan mental.

\section{Hubungan Antara Pekerjaan dengan Kejadian Diabetes Mellitus}

Hasil penelitian di atas sejalan juga dengan penelitian Endriani (2012) yaitu terdapat hubungan bermakna antara status pekerjaan dengan penyakit diabetes mellitus di RSUD Depok dengan diperoleh nilai $p$-value $=0.000$.

Pekerjaan dalam pemenuhan kebutuhan dapat diukur dari bidang pekerjaan yang ditekuni oleh seseorang baik pada kelompok responden yang bekerja sebagai petani, pedagang, PNS, guru, wiraswasta, buruh ataupun IRT, bahwa lingkungan pekerjaan dapat menjadikan seseorang berisiko terkena penyakit baik secara langsung maupun tidak langsung, yang salah satunya adalah penyakit diabetes mellitus (Sitomorang, 2009). Faktor pekerjaan mempengaruhi risiko diabetes mellitus, pekerjaan dengan aktivitas fisik ringan/rendah menyebabkan kurangnya pembakaran energi oleh tubuh sehingga kelebihan energi dalam tubuh akan disimpan dalam bentuk lemak dalam tubuh yang mengakibatkan obesitas yang merupakan salah satu faktor risiko diabetes mellitus (Suiraoka, 2012).

Berdasarkan jenis pekerjaan dimana seseorang yang memiliki kegiatan atau pekerjaan sehari-hari yang tinggi dengan aktivitas fisik yang kurang, jadwal makan dan tidur tidak teratur menjadi faktor resiko dalam meningkatnya penyakit diabetes mellitus. Kurang tidur seseorang dapat mengganggu keseimbangan hormon yang mengatur asupan makanan dan keseimbangan energi. Tidak sama halnya dengan seseorang bekerja sebagai petani ataupun buruh di lapangan dimana dalam melakukan aktivitas bekerja membutuhkan tenaga dan energi yang banyak sehingga dapat meningkatkan kecepatan pemulihan glukosa otot (seberapa banyak otot mengambil glukosa dari alirah darah) sehingga kelebihan energi dalam tubuh yang disimpan dalam bentuk lemak dalam tubuh yang mengakibatkan salah satu faktor risiko diabetes yaitu obesitas dapat ditekan (Suiraoka, 2012).

Dari hasil penelitian di atas peneliti berpendapat bahwa jenis pekerjaan mempengaruhi risiko terjadinya diabetes mellitus, pekerjaan dengan aktivitas fisik yang kurang dapat menyebabkan kurangnya pembakaran energi sehingga dapat menyebabkan kenaikan berat badan dan berisiko besar terkena diabetes melitus.

\section{KESIMPULAN}

Aktivitas fisik dan pekerjaan merupakan faktor yang berpengaruh terhadap kejadian diabetes mellitus. Diharapkan bagi masyarakat yang memiliki pekerjaan dengan aktivitas fisik yang rendah/ringan sebaiknya dapat memperhatikan waktu tertentu untuk melakukan peregangan atau dengan melakukan olahraga sepertilatihan aerobik, ketahanan atau kombinasi keduanya minimal 150 menit per minggu, atau sekitar 2-3x per minggu.

\section{DAFTAR PUSTAKA}

American Diabetes Association (ADA). (2012). Standards of Medical care In Diabetes Care. Diabetes Care Journal 35(1): 116-121.

Astuti, D. (2016). Pengaruh Senam Aerobik Terhadap Kadar Gula Darah Puasa Penderita Diabetes Mellitus Tipe 2 Pada Kelompok Prolanis UPT Puskesmas Wonogiri. [Skripsi]. Jakarta: Stikes Kusuma Husada Jakarta.

Barnes, D. E. (2011).Program Olahraga Diabetes. Yogyakarta: Citra Aji Parama.

Endriani A. (2012). Hubungan Faktor Sosial Ekonomi Dan Faktor Yang Tidak Dan Bisa Dimodifikasi Terhadap Diabetes Melitus Pada Lansia Dan Pralansia Di Kelurahan Depok Jaya, Depok Jawa Barat Pada Tahun 2012. [Skripsi]. Jakarta: Universitas Indonesia. 
Fharitz, R. M. (2018). Faktor-Faktor yang Berhubungan Dengan Penyakit Diabetes Mellitus Di Ruang Poli Interna Rsud Mokopido Kabupaten Tolitoli. [Skripsi]. Palu: Universitas Muhammadiyah Palu.

Gabby, M. (2017). Hubungan antara Status Sosio-Ekonomi dengan Kejadian Diabetes Mellitus Tipe 2 di Poliklinik Interna Blu RSUP Prof. Dr. R. D. Kandou Manado. [Skripsi]. Manado: Universitas Sam Ratulangi.

Irwan, D. (2010). Prevalensi dan Faktor Risiko Kejadian Diabetes Melitus Tipe 2 di Daerah Urban Indonesia (Analisa Data Sekunder Riskesdas 2007). Jakarta: Universitas Indonesia.

Kementerian Kesehatan. (2015). Penyakit, Pengendalian; Lingkungan, Penyehatan. Petunjuk Teknis Pengukuran Faktor Risiko Diabetes Melitus. Jakarta: Kementerian Kesehatan RI.

Nonita, S. (2019). Aktivitas Fisik Dan Hubungannya Dengan Kejadian Diabetes Melitus. Window of Health: Jurnal Kesehatan 2(4): 368-381.

Perkumpulan Endokrinologi Indonesia. (2015). Konsensus Pengendalian dan Pencegahan Diabetes MelitusMellitus Tipe 2 di Indonesia. Jakarta: PB PERKENI.

Remais JV, Guang Z. Guangwei L. (2012). Convergence of NonCommunicable and Infectious Diseases in Low- and MiddleIncome Countries. International Journal of Epidemiology 42(1): 221.

Risma, D. (2019). Gambaran Karakteristik Penderita Diabetes Mellitus Yang Berobat Jalan Ke Poli Interna Rsup H. Adam Malik Medan Tahun 2019. [Skripsi] Medan: Politeknik Kesehatan Kementerian Kesehatan Medan.

Riset Kesehatan Dasar. (2018). Laporan Nasional Riset Kesehatan Dasar 2018. Jakarta: Badan Penelitian Dan Pengembangan Kesehatan
Sitomorang, S. (2009). Diabetes Melitus Klasifikasi, Diagnosis, Dan Terapi. Jakarta: Gramedia Pustaka.

Skyler. J. S., Bakris, G.L., Bonifacio.E, Darsow.T, Eckel. R.H, Groop.L., Groop.P.H., dkk. (2017). Differentiation of diabetes by pathophysiology, natural history, and prognosis.NCBI Journal 66(2): 241-255.

Suiraoka, I. P. (2012). Penyakit Degeneratif. Mengenal, Mencegah Dan Mengurangi Faktor Risiko 9 Penyakit Degeneratif. Yogyakarta: Nuha Medika.

Tjokroprawiro, A. (2012). Garis Besar Pola Makan Dan Pola Hidup Sebagai Pendukung Terapi Diabetes Melitus. Plenary Lecture Journal, 11-13.

World Health Organization. (2010). Global Status Report on Noncommunicable Diseases 2010. Italy: World Health Organization. Available at: https://www.who.int/nmh/public ations/ncd_report2010/en/.

World Health Organization. (2016). Fact Sheet of Diabetes. Europe: World Health Organization. Available at:

www.euro.who.int/_data/assets /pdf_file/0010/305389/DiabetesFact-Sheet-en.pdf.

World Health Organization. (2016). Global Report On Diabetes. Swiss: World Health Organization. Available at: www.who.int/publications/i/item/ 9789241565257.

Zahtamal, C. F., Suyanto, R. T., \& Restuastuti, T. (2007). FaktorFaktor Risiko Pasien Diabetes Melitus. Berita kedokteran masyarakat 23(3): 142-147. 